\title{
Isolation and structural characterization of the milled-wood lignin from Paulownia fortunei wood
}

\author{
Jorge Rencoret $^{\mathrm{a}}$, Gisela Marques $^{\mathrm{a}}$, Ana Gutiérrez $^{\mathrm{a}}$, Lidia Nieto ${ }^{\mathrm{b}}$, \\ J. Jiménez-Barbero ${ }^{\mathrm{b}}$, Ángel T. Martínez ${ }^{\mathrm{b}}$, José C. del Río ${ }^{\mathrm{a}, *}$ \\ a Instituto de Recursos Naturales y Agrobiología de Sevilla (IRNAS), CSIC, Reina Mercedes 10, PO Box 1052, E-41080 Seville, Spain \\ b Centro de Investigaciones Biológicas (CIB), CSIC, Ramiro de Maeztu 9, E-28040 Madrid, Spain
}

\section{A R T I C L E I N F O}

\section{Article history:}

Received 26 January 2009

Received in revised form 5 March 2009

Accepted 6 March 2009

\section{Keywords:}

Paulownia fortunei

Milled-wood lignin (MWL)

Pyrolysis-GC/MS

2D-NMR

HSQC

\begin{abstract}
A B S T R A C T
The chemical structure of the milled-wood lignin isolated from Paulownia fortunei wood was investigated. The lignins were characterized by analytical pyrolysis and two-dimensional NMR that indicated a predominance of guaiacyl (G) over syringyl (S) units, and only showed small amounts of $p$-hydroxyphenyl (H) units, with a $\mathrm{H}: \mathrm{G}: \mathrm{S}$ molar ratio of 1:59:40. The heteronuclear single quantum correlation (HSQC) NMR spectrum gave additional information about the relative abundances of the different inter-unit linkages present in the lignin structure. Paulownia lignin showed a predominance of $\beta-0-4^{\prime}$ aryl ether linkages (62\% of total side-chains), followed by $\beta-\beta^{\prime}$ resinol-type (12\%) and $\beta-5^{\prime}$ phenylcoumaran-type structures (11\%) and with lower amounts of other condensed structures such as spirodienone (3\%) and dibenzodioxocin ( $2 \%$ ) structures. The high lignin content ( $\mathrm{ca}$. 23\% Klason lignin), together with the low S/G ratio and the abundance of condensed (carbon-carbon linked) structures (together with the low abundance of the most labile ether-linked structures) could contribute to the low reactivity of paulownia lignin during alkaline pulping.
\end{abstract}

(C) 2009 Elsevier B.V. All rights reserved.

\section{Introduction}

Paulownia is a fast-growing shade tree native to China and South-East Asia that is grown commercially for the production of hardwood timber (Bergmann, 1998). Paulownia wood has also been investigated as a promising raw material for the production of chemical pulp (Olson and Carpenter, 1985; Rai et al., 2000; Jiménez et al., 2005; Caparrós et al., 2007, 2008). The most suitable species of paulownia for this purpose is Paulownia fortunei, with an average fiber length of $1.42 \mathrm{~mm}$ (Rai et al., 2000). This species is characterized by its fast development and a uniform and regular growth (Ede et al., 1997). Under the appropriate conditions, a 5-7-year-old tree can reach about $15-20 \mathrm{~m}$ high and the annual production is as high as 150 tons/ha (Jiménez et al., 2005).

The growing interest in paulownia wood as a promising chemical feedstock has stimulated recent studies on the structural characteristic of its main constituents. Among these, the composition and structural features of xylans and extractives isolated from paulownia wood have recently been addressed (Gonçalves et al., 2008; Silvestre et al., 2005). However, there is a lack of stud-

\footnotetext{
* Corresponding author. Tel.: +34 95462 4711; fax: +34 954624002 .

E-mail address: delrio@irnase.csic.es (J.C. del Río).
}

ies regarding the structural characteristics of the lignin polymer, despite its great influence during the industrial processing of wood, such as pulping and papermaking. Pulping and bleaching performances are highly dependent on the relative content, structure and reactivity of the three wood structural biopolymers, cellulose, hemicelluloses and lignin. Particularly, the lignin content and its composition in terms of $p$-hydroxyphenyl $(H)$, guaiacyl $(G)$ and syringyl (S) moieties as well as the nature of the different inter-unit linkages present in its structure are important factors in pulp production affecting the delignification rates, chemical consumption and pulp yields. The lower the lignin content and the proportion of G-lignin and condensed units, the less energy and chemicals are needed for alkaline pulping and subsequent bleaching. It has already been shown that higher $S / G$ ratios in hardwoods implied higher delignification rates, less alkali consumption and therefore higher pulp yields (González-Vila et al., 1999; del Río et al., 2005).

It is therefore clear that, in order to optimize the use of paulownia wood as raw material for paper pulp manufacture, more information needs to be acquired on the composition and structure of its lignin polymer. In this paper, we report the composition and structural characteristics of the lignin from the wood of $P$. fortunei. For this purpose, the milled-wood lignin (MWL) of paulownia wood was isolated and characterized by pyrolysis-gas chromatography/mass spectrometry (Py-GC/MS) and two-dimensional nuclear magnetic resonance (2D-NMR) spectroscopy. 


\section{Materials and methods}

\subsection{Samples}

The wood was collected from 3-year-old trees of Paulownia fortunei, provided by the University of Huelva, Spain. The air-dried wood was milled using a knife mill (Janke and Kunkel, Analysenmühle), and successive extracted with acetone in a Soxhlet apparatus for $8 \mathrm{~h}$ and hot water $\left(3 \mathrm{~h}\right.$ at $\left.100^{\circ} \mathrm{C}\right)$. Klason lignin content was estimated as the residue after sulfuric acid hydrolysis of the pre-extracted material according to Tappi rule T222 om-88 (Tappi, 2004). The MWL samples (Björkman, 1956) were obtained from grounded wood prepared in a Retsch cutting mill to pass through a 100-mesh screen. This sawdust was successively extracted with acetone for $8 \mathrm{~h}$ in a Soxhlet extractor and with hot water $\left(100^{\circ} \mathrm{C}\right)$ for $3 \mathrm{~h}$. The extractive free sawdust was finely ball-milled in a Retsch S100 centrifugal ball mill with toluene $(c a .50 \mathrm{~h})$ using agate jar and balls. After this treatment the milled wood was submitted to an extraction $(3 \times 12 \mathrm{~h})$ with dioxane-water $(9: 1, \mathrm{v} / \mathrm{v})(25 \mathrm{ml}$ of solvent/g of milled wood). The solution was centrifuged and the supernatant subsequently evaporated at $40^{\circ} \mathrm{C}$ at reduced pressure until dryness. The residue obtained (raw MWL) was redissolved in a solution of acetic acid/water 9:1 (v/v) $(20 \mathrm{ml}$ of solvent/g of raw MWL). The solution was then precipitated in water and the precipitated residue was separated by centrifugation, milled in an agate mortar and subsequently dissolved in a solution of 1,2-dicloromethane:ethanol $(1: 2, \mathrm{v} / \mathrm{v})$. The mixture was then centrifuged to eliminate the insoluble material, the supernatant was precipitated in diethyl ether and the obtained residue was separated by centrifugation. This residue was then resuspended in petroleum ether and centrifuged again to obtain the final purified MWL fraction, which was dried under a $\mathrm{N}_{2}$ current. The final yield was ca. $20 \%$ of the original Klason lignin content. Underivatized and acetylated MWL, after $48 \mathrm{~h}$ treatment in acetic anhydride-pyridine (1:2) were analyzed as described below.

\section{2. $P y-G C / M S$}

Pyrolysis of MWL (approximately $100 \mu \mathrm{g}$ ) was performed with a 2020 micro-furnace pyrolyzer (Frontier Laboratories Ltd.) connected to an Agilent $6890 \mathrm{GC} / \mathrm{MS}$ system equipped with a DB-1701 (Agilent $\mathrm{J} \& \mathrm{~W}$ ) fused-silica capillary column $(30 \mathrm{~m} \times 0.25 \mathrm{~mm}$ i.d., $0.25 \mu \mathrm{m}$ film thickness) and an Agilent 5973 mass selective detector $\left(\mathrm{EI}\right.$ at $70 \mathrm{eV}$ ). The pyrolysis was performed at $500^{\circ} \mathrm{C}$. The oven temperature was programmed from $40^{\circ} \mathrm{C}(1 \mathrm{~min})$ to $300^{\circ} \mathrm{C}$ at $6^{\circ} \mathrm{C} \mathrm{min}^{-1}$ (10 min). He was the carrier gas $\left(1 \mathrm{ml} \mathrm{min}^{-1}\right)$. The compounds were identified by comparing their mass spectra with those of the Wiley and NIST libraries and reported in the literature (Faix et al., 1990; Ralph and Hatfield, 1991). Peak molar areas were calculated for the lignin-derived products, the summed areas were normalized to 100 , and the data for two repetitive analyses were averaged and expressed as percentages.

\subsection{NMR spectroscopy}

2D-NMR spectra of underivatized and "in vitro" acetylated MWL were recorded at $25^{\circ} \mathrm{C}$ in a Bruker AVANCE $500 \mathrm{MHz}$, equipped with a z-gradient triple resonance probe. Around $40 \mathrm{mg}$ of $\mathrm{MWL}$ were dissolved in $0.75 \mathrm{~mL}$ of dimethylsulfoxide (DMSO)- $d_{6}$, and HSQC (heteronuclear single quantum correlation) spectrum was recorded. The spectral widths were 5000 and $13,200 \mathrm{~Hz}$ for the ${ }^{1} \mathrm{H}$ and ${ }^{13} \mathrm{C}$ dimensions, respectively. The number of collected complex points was 2048 for ${ }^{1} \mathrm{H}$ dimension, with a recycle delay of $5 \mathrm{~s}$. The number of transients was 64 , and 256 time increments were always recorded in ${ }^{13} \mathrm{C}$ dimension. The ${ }^{1} J_{\mathrm{CH}}$ used was $140 \mathrm{~Hz}$. The $J$-coupling evolution delay was set to $3.2 \mathrm{~ms}$. Squared cosine-bell apodization function was applied in both dimensions. Prior to Fourier transformation, the data matrixes were zero filled up to 1024 points in the ${ }^{13} \mathrm{C}$ dimension. The central solvent (DMSO) peak was used as an internal reference $\left(\delta_{\mathrm{C}} 40.1 ; \delta_{\mathrm{H}} 2.50 \mathrm{ppm}\right)$. HSQC cross-signals were assigned by comparing with the literature (Ralph et al., 1999, 2004b; Liitiä et al., 2003; Capanema et al., 2004, 2005; Ibarra et al., 2007a,b; Rencoret et al., 2008; Martínez et al., 2008; del Río et al., 2008).

A semiquantitative analysis of the intensities of the HSQC crosssignal intensities was performed (Liitiä et al., 2003; Heikkinen et al. 2003; Zhang and Gellerstedt, 2007). Since the cross-signal intensity depends on the particular ${ }^{1} J_{\mathrm{CH}}$ value, as well on the $T_{2}$ relaxation time, a direct analysis of the intensities is elusive. Thus, integration was performed separately for the different regions of the spectra, which contain signals corresponding to chemically analogous $\mathrm{C}-\mathrm{H}$ pairs, with similar ${ }^{1} J_{\mathrm{CH}}$ coupling values. In the aliphatic oxygenated region, inter-unit linkages were estimated from $\mathrm{C}_{\alpha}-\mathrm{H}_{\alpha}$ correlations, except for structures I described below where the $\mathrm{C}_{\gamma}-\mathrm{H}_{\gamma}$ correlations were used, and the relative abundance of side-chains involved in the different substructures and terminal structures were calculated. In the aromatic region, $\mathrm{C}-\mathrm{H}$ correlations from $\mathrm{S}$ and $\mathrm{G}$ units were used to estimate the $S / G$ ratio, and the comparison of the intensities of the $\mathrm{C}_{\beta}-\mathrm{H}_{\beta}$ correlations of $\mathbf{I}$ and $\mathbf{J}$ structures were used to estimate the abundances of the latest. The amount of phenolic and alcoholic hydroxyls in MWL was estimated by integrating the methyl signals of the corresponding acetates, after "in vitro" acetylation (compared with underivatized MWL). The percentage of phenolic aromatic units was calculated by referring the phenolic acetate signal to the total number of aromatic rings $(H+G+S)$, which was estimated from the intensity of the methoxyl signal $\left(\delta_{\mathrm{C}} / \delta_{\mathrm{H}} 56 / 3.7 \mathrm{ppm}\right)$ and taking into account the $\mathrm{H}: \mathrm{G}: \mathrm{S}$ ratio.

\section{Results and discussion}

The lignin content of $P$. fortunei, estimated as Klason lignin, is relatively high $(22.7 \%)$, in agreement with previous works (Jiménez et al., 2005; Gonçalves et al., 2008). This content is comparable to other hardwoods commonly used for papermaking, such as eucalypt, with lignin content around 18-23\% (Rencoret et al., 2007). However, the delignification reactions and therefore the pulping efficiency is not only affected by the lignin content but is also greatly influenced by the lignin composition and structure. Therefore, we have thoroughly studied the lignin composition and structure of paulownia wood. For this, the MWL was isolated by aqueous dioxane extraction from finely ball-milled wood according to the classical lignin isolation procedure (Björkman, 1956). MWL is considered to be representative of the whole native lignin in the plant, in spite of its low yield and the possibility of some modifications during milling (Holtman et al., 2006). The lignin composition was analyzed by means of Py-GC/MS, which allows for the rapid characterization of the lignin H:G:S composition, and then a more detailed characterization of the lignin substructures present was performed by 2D-NMR of the isolated MWL, that gives information on the different inter-unit linkages present.

\section{1. $P y-G C / M S$}

Py-GC/MS is a rapid and sensitive technique for analyzing the composition of lignin (Faix et al., 1990; Ralph and Hatfield, 1991). It has been widely applied for the calculation of $S / G$ ratios in different hardwoods (Rodrigues et al., 1999; Yokoi et al., 1999, 2001; del Río et al., 2005; Rencoret et al., 2007, 2008; Marques et al., 2008). The pyrogram of paulownia MWL is shown in Fig. 1 and the identities and relative molar abundances of the released lignin compounds are listed in Table 1. 


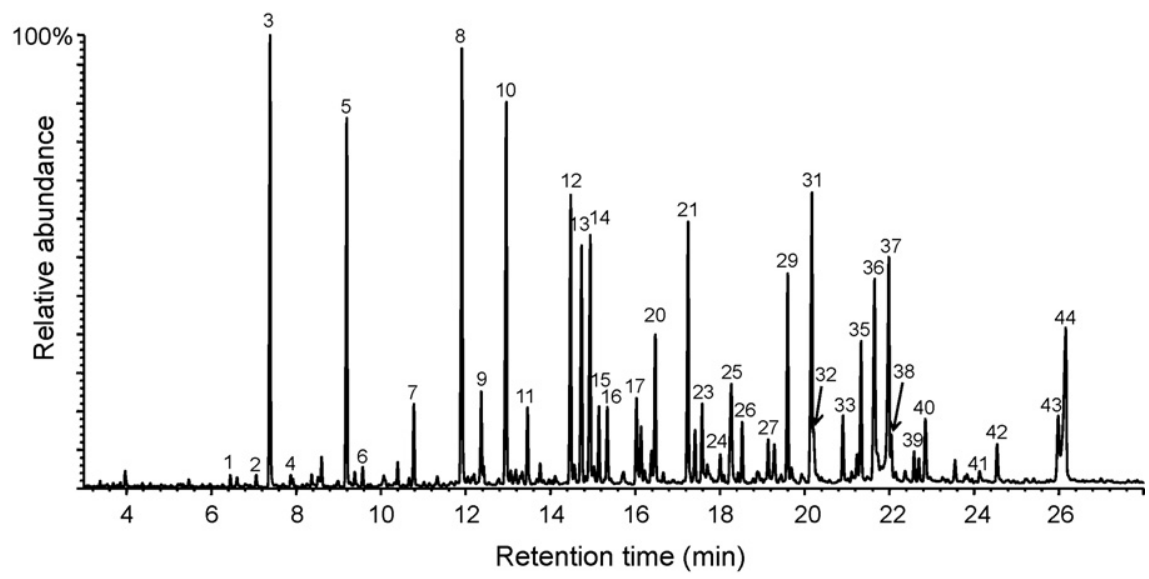

Fig. 1. Py-GC/MS chromatogram of the MWL isolated from Paulownia fortunei wood. The numbers refer to the compounds listed in Table 1.

Table 1

Identification and relative molar abundance (\%) of the compounds identified in the Py-GC/MS of MWL from Paulownia fortunei wood.

\begin{tabular}{|c|c|c|c|c|}
\hline Label & Compound & MW (amu) & Relative abundance (\%) & Origin \\
\hline 1 & 4-Hydroxybenzaldehyde & 122 & 0.2 & $\mathrm{H}$ \\
\hline 2 & Phenol & 94 & 0.3 & $\mathrm{H}$ \\
\hline 3 & Guaiacol & 124 & 9.0 & G \\
\hline 4 & Methylphenol & 108 & 0.2 & $\mathrm{H}$ \\
\hline 5 & 4-Methylguaiacol & 138 & 6.8 & G \\
\hline 6 & Dimethylphenol & 122 & 0.3 & $\mathrm{H}$ \\
\hline 7 & 4-Ethylguaiacol & 152 & 1.5 & G \\
\hline 8 & 4-Vinylguaiacol & 150 & 8.3 & G \\
\hline 9 & Eugenol & 164 & 1.5 & G \\
\hline 10 & Syringol & 154 & 7.5 & $\mathrm{~S}$ \\
\hline 11 & cis-Isoeugenol & 164 & 1.3 & G \\
\hline 12 & trans-Isoeugenol & 164 & 4.8 & G \\
\hline 13 & 4-Methylsyringol & 168 & 4.1 & $S$ \\
\hline 14 & Vanillin & 152 & 4.8 & G \\
\hline 15 & Propine-guaiacol & 162 & 1.3 & G \\
\hline 16 & Propine-guaiacol & 162 & 1.4 & G \\
\hline 17 & Homovanillin & 166 & 1.7 & G \\
\hline 18 & 4-Ethylsyringol & 182 & 0.9 & $\mathrm{~S}$ \\
\hline 19 & Vanillic acid methyl ester & 182 & 0.5 & G \\
\hline 20 & Acetoguaiacone & 166 & 2.6 & G \\
\hline 21 & 4-Vinylsyringol & 180 & 4.2 & $\mathrm{~S}$ \\
\hline 22 & Guaiacyl-acetone & 180 & 0.9 & G \\
\hline 23 & 4-Allylsyringol & 194 & 1.1 & $\mathrm{~S}$ \\
\hline 24 & Propiovanillone & 180 & 0.5 & G \\
\hline 25 & Guaiacyl vinyl ketone & 178 & 2.2 & G \\
\hline 26 & cis-Propenylsyringol & 194 & 0.8 & $S$ \\
\hline 27 & Propine-syringol & 192 & 0.6 & $\mathrm{~S}$ \\
\hline 28 & Propine-syringol & 192 & 0.7 & $\mathrm{~S}$ \\
\hline 29 & trans-Propenylsyringol & 194 & 3.0 & $\mathrm{~S}$ \\
\hline 30 & Dihydroconiferyl alcohol & 182 & 0.2 & G \\
\hline 31 & Syringaldehyde & 182 & 5.3 & $\mathrm{~S}$ \\
\hline 32 & cis-Coniferyl alcohol & 180 & 0.8 & G \\
\hline 33 & Homosyringaldehyde & 196 & 1.0 & $S$ \\
\hline 34 & Syringic acid methyl ester & 212 & 0.3 & $\mathrm{~S}$ \\
\hline 35 & Acetosiryngone & 196 & 2.0 & $\mathrm{~S}$ \\
\hline 36 & trans-Coniferyl alcohol & 180 & 4.3 & G \\
\hline 37 & trans-Coniferaldehyde & 178 & 4.7 & G \\
\hline 38 & Syringylacetone & 210 & 0.5 & $\mathrm{~S}$ \\
\hline 39 & Propiosyringone & 210 & 0.4 & $\mathrm{~S}$ \\
\hline 40 & Syringyl vinyl ketone & 208 & 1.0 & $\mathrm{~S}$ \\
\hline 41 & Dihydrosinapyl alcohol & 212 & 0.2 & $\mathrm{~S}$ \\
\hline 42 & cis-Sinapyl alcohol & 210 & 0.6 & $\mathrm{~S}$ \\
\hline 43 & trans-Sinapyl alcohol & 210 & 1.5 & $\mathrm{~S}$ \\
\hline \multirow[t]{5}{*}{44} & trans-Sinapaldehyde & 208 & 4.0 & $\mathrm{~S}$ \\
\hline & & $\% \mathrm{H}$ & 1.1 & \\
\hline & & $\% \mathrm{G}$ & 59.1 & \\
\hline & & $\% \mathrm{~S}$ & 39.8 & \\
\hline & & $\mathrm{S} / \mathrm{G}$ & 0.67 & \\
\hline
\end{tabular}

Among them, guaiacol and syringol-type phenols, derived from the guaiacyl $(G)$ and syringyl $(S)$ lignin units respectively, typical of hardwoods, were identified. Only small amounts (ca. $1 \%$ ) of phenol-type compounds derived from $p$-hydroxycinnamyl $(\mathrm{H})$ lignin units could be detected among the released compounds. The most important compounds identified were guaiacol (3), 4-methylguaiacol (5), 4-vinylguaiacol (8), syringol (10), trans-isoeugenol (12), 4-methylsyringol (13), vanillin (14), 4vinylsyringol (21), syringaldehyde (31), trans-4-propenylsyringol (29), trans-coniferyl alcohol (36), trans-coniferaldehyde (37) and trans-sinapaldehyde (44). Surprisingly, the G-lignin-derived phenols were released in higher abundances than the respective S-lignin-derived phenols, which is unusual for a hardwood, with a $\mathrm{H}: \mathrm{G}: \mathrm{S}$ composition of $1: 59: 40$, and a molar $\mathrm{S} / \mathrm{G}$ ratio of 0.66 . The predominance of G-lignin units in paulownia wood, in contrast to other hardwood species, such as eucalypt, with a high predominance of S-lignin units (Rencoret et al., 2007), is unfavorable for alkaline delignification due to the lower reactivity of the G-lignin compared to S-lignin in alkaline systems (Chang and Sarkanen, 1973; Tsutsumi et al., 1995). Therefore, the low lignin S/G ratio of paulownia will adversely affect the pulping efficiency. It has already been shown for other hardwoods, such as eucalypt woods, that higher S/G ratios imply higher delignification rates, less alkali consumption and therefore higher pulp yield (González-Vila et al., 1999; del Río et al., 2005). Therefore, for paulownia wood, the low S/G ratio, together with its high lignin content (ca. 23\%), would make this wood more resistant to alkaline cooking, requiring a higher alkali charge and therefore implying a lower pulp yield.

\section{2. $2 D-N M R$}

2D-NMR is a powerful tool for lignin structural characterization providing information of the structure of the inter-unit linkages present (Balakshin et al., 2003, 2005; Capanema et al., 2001, 2004, 2005; Ibarra et al., 2007a,b; Ralph et al., 1999, 2004b; Rencoret et al., 2008; del Río et al., 2008; Martínez et al., 2008) and enabled the description of new lignin substructures such as the dibenzodioxocins (Karhunen et al., 1995) and the spirodienones (Zhang and Gellerstedt, 2001; Zhang et al., 2006) during recent years.

The HSQC NMR spectrum of paulownia MWL showed three regions corresponding to aliphatic, side-chain and aromatic ${ }^{13} \mathrm{C}-{ }^{1} \mathrm{H}$ correlations. The aliphatic (non-oxygenated) region showed signals with no structural information, excepting those of the acetate methyls that were used to estimate the phenolic and aliphatic hydroxyls in MWL after "in vitro" acetylation (signals with $\delta_{\mathrm{C}} / \delta_{\mathrm{H}}$ around $21 / 2.2-2.3$ and $21 / 1.8-2.1 \mathrm{ppm}$, respectively). The sidechain region $\left(\delta_{\mathrm{C}} / \delta_{\mathrm{H}} 50-95 / 2.5-6.0 \mathrm{ppm}\right)$ and the aromatic region 

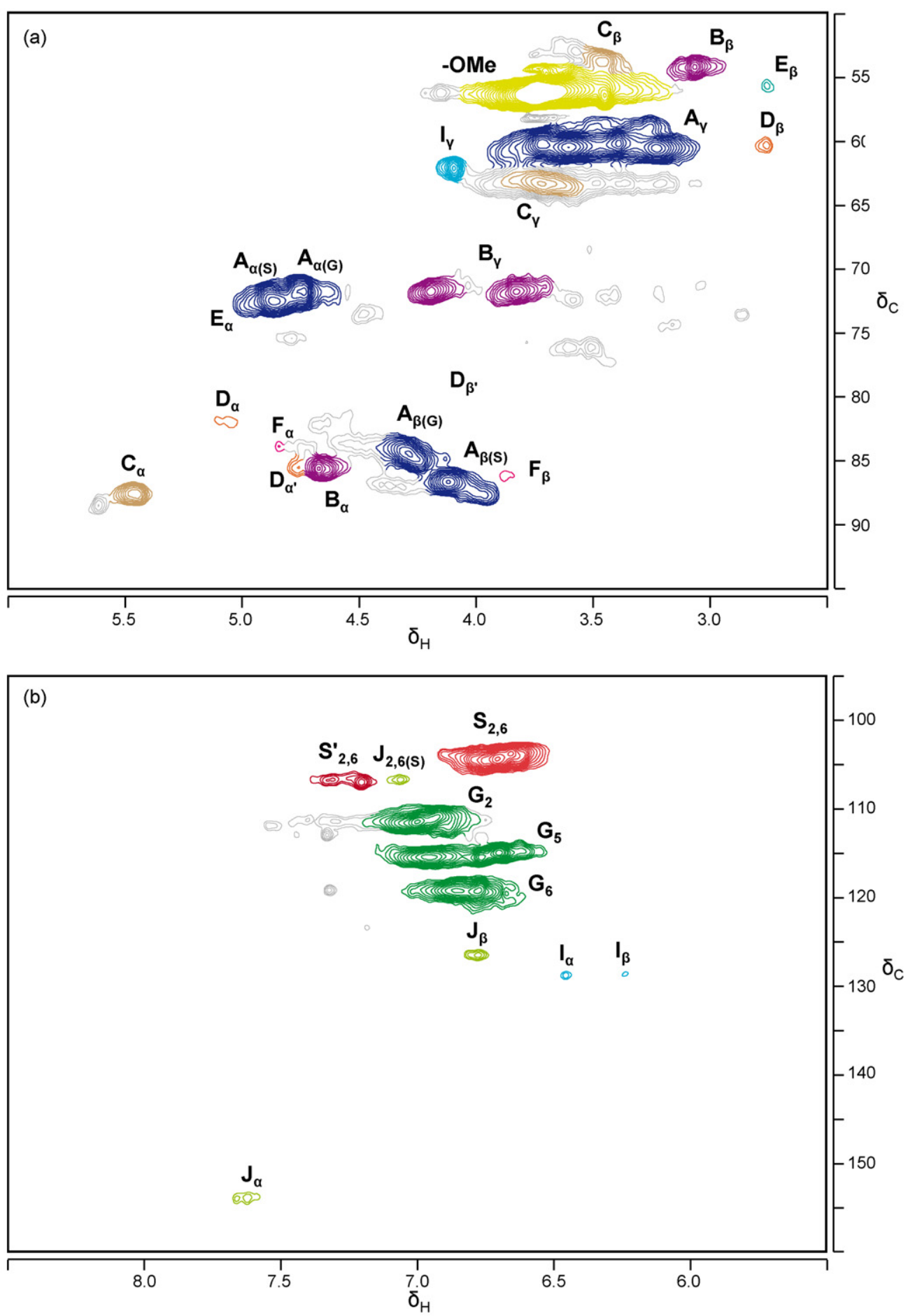

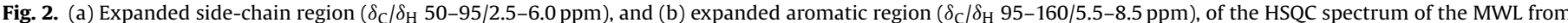

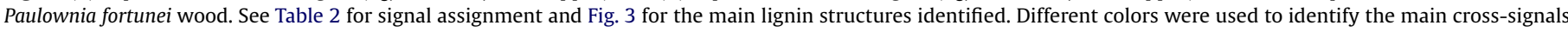
and their corresponding structures.

$\left(\delta_{\mathrm{C}} / \delta_{\mathrm{H}} 95-160 / 5.5-8.5 \mathrm{ppm}\right)$ of the HSQC spectrum of paulownia MWL are shown in Fig. 2. The main lignin cross-signals assigned in the HSQC spectrum are listed in Table 2 and the main substructures present are depicted in Fig. 3.

The side-chain region of the spectrum (Fig. 2a) gives useful information about the different inter-unit linkages present in paulownia lignin. The spectrum shows prominent signals corresponding to $\beta-\mathrm{O}-4^{\prime}$ aryl ether linkages (substructure A). The $\mathrm{C}_{\alpha}-\mathrm{H}_{\alpha}$ correlations in $\beta-0-4^{\prime}$ substructures were observed at $\delta_{\mathrm{C}} / \delta_{\mathrm{H}} 71.6 / 4.74$ and $72.4 / 4.86 \mathrm{ppm}$ for structures linked to $\mathrm{G}$ or S-lignin units, respectively. Likewise, the $\mathrm{C}_{\beta}-\mathrm{H}_{\beta}$ correlations were observed at $\delta_{\mathrm{C}} / \delta_{\mathrm{H}} 84.1 / 4.28 \mathrm{ppm}$ for $\beta-0-4^{\prime}$ structures linked to $\mathrm{G}$ lignin units and at $\delta_{\mathrm{C}} / \delta_{\mathrm{H}} 86.4 / 4.11 \mathrm{ppm}$ for $\beta-0-4^{\prime}$ structures linked to $\mathrm{S}$ lignin units. The $\mathrm{C}_{\gamma}-\mathrm{H}_{\gamma}$ correlations in $\beta-\mathrm{O}-4^{\prime}$ substructures were observed at $\delta_{\mathrm{C}} / \delta_{\mathrm{H}} 60.1 / 3.40$ and $3.72 \mathrm{ppm}$, partially overlapped with other signals. In addition to $\beta-0-4^{\prime}$ aryl ether substructures, other linkages were also observed in important amounts. Strong signals for resinol $\left(\beta-\beta^{\prime} / \alpha-0-\gamma^{\prime} / \gamma-O-\alpha^{\prime}\right.$ linkages) substructures (B) 
<smiles>COc1cc(C(C)(C)C)cc(OC)c1OC(CO)C(O)c1cc(OC)c(OC(C)(C)C)c(OC)c1</smiles>

A

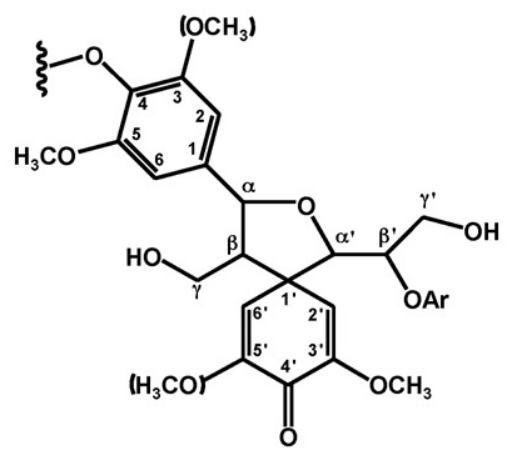<smiles>CCOc1c(OC)cc(C2O[CH]C3C(c4cc(OC)c(OC(C)C)c(OC)c4)OC[C@@H]23)cc1OC</smiles>

B<smiles>CCOc1c(OC)cc(C2Oc3c(OC)cc(C)cc3C2CO)cc1OC</smiles><smiles>COc1cc(C(O)C(CO)c2cc(OC)c(OC)c(OC)c2)cc(OC)c1OC</smiles>

E

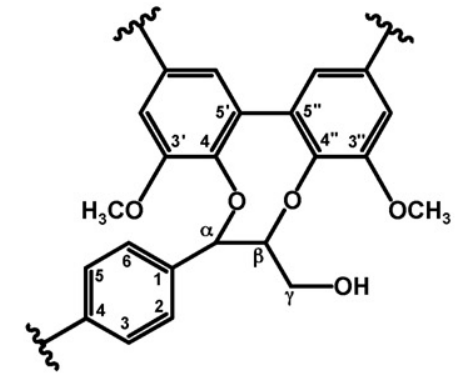

$\mathbf{F}$<smiles>CCOc1c(OC)cc(C=CCO)cc1OC</smiles>

|<smiles>CCOc1c(OC)cc(C=CC=O)cc1OC</smiles>

$J$<smiles>CCOc1cc(C(C)O)ccc1OC</smiles>

G<smiles>CCOc1c(OC)cc(C(C)O)cc1OC</smiles>

S

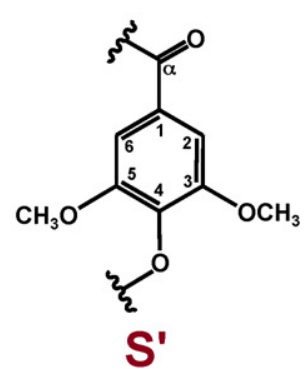

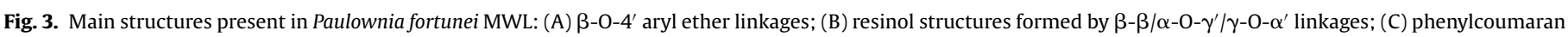

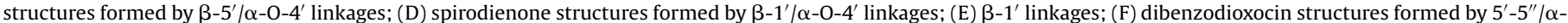
O-4'/ $\beta$-O-4" linkages; (I) cinnamyl alcohol end-groups; (J) cinnamaldehyde end-groups; (G) guaiacyl units; $(\mathrm{S})$ syringyl units; $\left(\mathrm{S}^{\prime}\right) \mathrm{C}_{\alpha}$-oxidized syringyl units.

were observed in the spectrum, with their $\mathrm{C}_{\alpha}-\mathrm{H}_{\alpha}, \mathrm{C}_{\beta}-\mathrm{H}_{\beta}$ and the double $\mathrm{C}_{\gamma}-\mathrm{H}_{\gamma}$ correlations at $\delta_{\mathrm{C}} / \delta_{\mathrm{H}} 85.5 / 4.67,54.1 / 3.06$ and $71.7 / 3.83$ and $4.19 \mathrm{ppm}$, respectively. Phenylcoumaran $\left(\beta-5^{\prime} / \alpha-0-4^{\prime}\right.$ linkages) substructures $(\mathbf{C})$ were also found in important amounts in paulownia MWL, the signals for their $\mathrm{C}_{\alpha}-\mathrm{H}_{\alpha}$ and $\mathrm{C}_{\beta}-\mathrm{H}_{\beta}$ correlations being observed at $\delta_{\mathrm{C}} / \delta_{\mathrm{H}} 87.4 / 5.47$ and $53.7 / 3.46 \mathrm{ppm}$, respectively, and that of $\mathrm{C}_{\gamma}-\mathrm{H}_{\gamma}$ correlation overlapping with other signals around $\delta_{\mathrm{C}} / \delta_{\mathrm{H}} 63.2 / 3.72 \mathrm{ppm}$. Small signals corresponding to spirodienone $\left(\beta-1^{\prime} / \alpha-O-\alpha^{\prime}\right.$ linkages $)$ substructures $(\mathbf{D})$ could also be observed in the spectra, their $\mathrm{C}_{\alpha}-\mathrm{H}_{\alpha}, \mathrm{C}_{\alpha^{\prime}}-\mathrm{H}_{\alpha^{\prime}}, \mathrm{C}_{\beta}-\mathrm{H}_{\beta}$ and $\mathrm{C}_{\beta^{\prime}}-\mathrm{H}_{\beta^{\prime}}$ correlations being at $\delta_{C} / \delta_{\mathrm{H}} 81.7 / 5.09,86.6 / 4.39,60.3 / 2.75$ and $79.8 / 4.11 \mathrm{ppm}$, respectively. Other small signals in the side-chain region of the HSQC spectra corresponded to $\mathrm{C}_{\beta}-\mathrm{H}_{\beta}$ correlations (at $\delta_{\mathrm{C}} / \delta_{\mathrm{H}} 55.6 / 2.76 \mathrm{ppm}$ ) of conventional $\beta-1^{\prime}$ substructures (E) (Lundquist, 1987). Interestingly, dibenzodioxocin $\left(5^{\prime}-5^{\prime \prime} / \alpha-O-\right.$ $4^{\prime} / \beta-0-4^{\prime \prime}$ linkages) structures (F) could also be observed in the
HSQC spectrum of paulownia MWL, although in low amounts, with their $\mathrm{C}_{\alpha}-\mathrm{H}_{\alpha}$ and $\mathrm{C}_{\beta}-\mathrm{H}_{\beta}$ correlations at $\delta_{\mathrm{C}} / \delta_{\mathrm{H}} 83.6 / 4.83$ and $85.9 / 3.88$ ppm, respectively. Dibenzodioxocins are important lignin structures in softwoods (Karhunen et al., 1995; Ralph et al., 2004a) where they act as branching points, but have rarely been found in hardwoods (Ämmälahti et al., 1998; Kukkola et al., 2004). Finally, other small signals observed in the HSQC spectrum are the $\mathrm{C}_{\gamma}-\mathrm{H}_{\gamma}$ correlations (at $\delta_{\mathrm{C}} / \delta_{\mathrm{H}} 61.9 / 4.09 \mathrm{ppm}$ ) assigned to cinnamyl alcohol end-groups (I). The olefinic correlations of the cinnamyl structures were observed in the aromatic region of the spectrum.

The main cross-signals in the aromatic region of the HSQC spectrum (Fig. 2b) corresponded mainly to the benzenic rings of the different lignin units. Cross-signals from syringyl (S) and guaiacyl (G) lignin units could be observed in the spectrum. The S-lignin units showed a prominent signal for the $\mathrm{C}_{2,6}-\mathrm{H}_{2,6}$ correlation at $\delta_{\mathrm{C}} / \delta_{\mathrm{H}} 104.7 / 6.69 \mathrm{ppm}$, while the $\mathrm{G}$ units showed different corre- 
Table 2

Assignments of ${ }^{13} \mathrm{C}-{ }^{1} \mathrm{H}$ correlation signals in the HSQC spectrum of the MWL from Paulownia fortunei wood.

\begin{tabular}{|c|c|c|}
\hline Labels & $\delta_{\mathrm{C}} / \delta_{\mathrm{H}}(\mathrm{ppm})$ & Assignment \\
\hline $\mathrm{C}_{\beta}$ & $53.7 / 3.46$ & $\begin{array}{l}\mathrm{C}_{\beta}-\mathrm{H}_{\beta} \text { in phenylcoumaran substructures } \\
\text { (C) }\end{array}$ \\
\hline $\mathrm{B}_{\beta}$ & $54.1 / 3.06$ & $\mathrm{C}_{\beta}-\mathrm{H}_{\beta}$ in resinol substructures (B) \\
\hline $\mathrm{E}_{\beta}$ & $55.6 / 2.76$ & $\mathrm{C}_{\beta}-\mathrm{H}_{\beta}$ in $\beta-1^{\prime}$ substructures $(\mathbf{E})$ \\
\hline -OMe & $56.2 / 3.73$ & $\mathrm{C}-\mathrm{H}$ in methoxyls \\
\hline $\mathrm{A}_{\gamma}$ & $60.1 / 3.40$ and 3.72 & $\mathrm{C}_{\gamma} \mathrm{H}_{\gamma}$ in $\beta-\mathrm{O}-4^{\prime}$ substructures (A) \\
\hline $\mathrm{D}_{\beta}$ & $60.3 / 2.75$ & $\mathrm{C}_{\beta}-\mathrm{H}_{\beta}$ in spirodienone substructures (D) \\
\hline $\mathrm{I}_{\gamma}$ & $61.9 / 4.09$ & $\begin{array}{l}\mathrm{C}_{\gamma}-\mathrm{H}_{\gamma} \text { in cinnamyl (sinapyl/coniferyl) } \\
\text { alcohol end-groups (I) }\end{array}$ \\
\hline $\mathrm{C}_{\gamma}$ & $63.2 / 3.72$ & $\begin{array}{l}\mathrm{C}_{\gamma}-\mathrm{H}_{\gamma} \text { in phenylcoumaran substructures } \\
\text { (C) }\end{array}$ \\
\hline$A_{\alpha(G)}$ & $71.6 / 4.74$ & $\mathrm{C}_{\alpha}-\mathrm{H}_{\alpha}$ in $\beta-\mathrm{O}-4^{\prime}$ linked to a $\mathrm{G}$ unit $(\mathbf{A})$ \\
\hline $\mathrm{B}_{\gamma}$ & $71.7 / 3.83$ and 4.19 & $\mathrm{C}_{\gamma}-\mathrm{H}_{\gamma}$ in resinol substructures $(\mathbf{B})$ \\
\hline$A_{\alpha(S)}$ & $72.4 / 4.86$ & $\mathrm{C}_{\alpha}-\mathrm{H}_{\alpha}$ in $\beta-\mathrm{O}-4^{\prime}$ linked to a $\mathrm{S}$ unit (A) \\
\hline $\mathrm{D}_{\beta^{\prime}}$ & $79.8 / 4.11$ & $\mathrm{C}_{\beta^{\prime}}-\mathrm{H}_{\beta^{\prime}}$ in spirodienone substructures (D) \\
\hline $\mathrm{D}_{\alpha}$ & $81.7 / 5.09$ & $\mathrm{C}_{\alpha} \mathrm{H}_{\alpha}$ in spirodienone substructures $(\mathbf{D})$ \\
\hline $\mathrm{F}_{\alpha}$ & $83.6 / 4.83$ & $\begin{array}{l}\mathrm{C}_{\alpha}-\mathrm{H}_{\alpha} \text { in } 5-5^{\prime} \text { (dibenzodioxocin) } \\
\text { substructures }(\mathbf{F})\end{array}$ \\
\hline$A_{\beta(G)}$ & $84.1 / 4.28$ & $\mathrm{C}_{\beta}-\mathrm{H}_{\beta}$ in $\beta-0-4^{\prime}$ linked to a $\mathrm{G}$ unit (A) \\
\hline $\mathrm{B}_{\alpha}$ & $85.5 / 4.67$ & $\mathrm{C}_{\alpha}-\mathrm{H}_{\alpha}$ in resinol substructures (B) \\
\hline $\mathrm{F}_{\beta}$ & $85.9 / 3.88$ & $\begin{array}{l}\mathrm{C}_{\beta}-\mathrm{H}_{\beta} \text { in } 5-5^{\prime} \text { (dibenzodioxocin) } \\
\text { substructures }(\mathbf{F})\end{array}$ \\
\hline $\mathrm{D}_{\alpha^{\prime}}$ & $86.6 / 4.39$ & $\mathrm{C}_{\alpha^{\prime}} \mathrm{H}_{\alpha^{\prime}}$ in spirodienone substructures (D) \\
\hline$A_{\beta(S)}$ & $86.4 / 4.11$ & $\mathrm{C}_{\beta}-\mathrm{H}_{\beta}$ in $\beta-\mathrm{O}-4^{\prime}$ linked to a $\mathrm{S}$ unit $(\mathbf{A})$ \\
\hline $\mathrm{C}_{\alpha}$ & $87.4 / 5.47$ & $\begin{array}{l}\mathrm{C}_{\alpha}-\mathrm{H}_{\alpha} \text { in phenylcoumaran substructures } \\
\text { (C) }\end{array}$ \\
\hline $\mathrm{S}_{2,6}$ & $104.7 / 6.69$ & $\mathrm{C}_{2,6}-\mathrm{H}_{2,6}$ in etherified syringyl units $(\mathbf{S})$ \\
\hline $\mathrm{J}_{2,6(S)}$ & $106.8 / 7.06$ & $\mathrm{C}_{2,6}-\mathrm{H}_{2,6}$ in sinapaldehyde end-groups $(\mathbf{J})$ \\
\hline $\mathrm{S}_{2,6}^{\prime}$ & 107.0/7.32 and 7.19 & $\begin{array}{l}\mathrm{C}_{2,6}-\mathrm{H}_{2,6} \text { in oxidized }\left(\mathrm{C}_{\alpha}=\mathrm{O}\right) \text { phenolic } \\
\text { syringyl units }\left(\mathbf{S}^{\prime}\right)\end{array}$ \\
\hline $\mathrm{G}_{2}$ & $111.6 / 6.99$ & $\mathrm{C}_{2}-\mathrm{H}_{2}$ in guaiacyl units $(\mathbf{G})$ \\
\hline $\mathrm{G}_{5}$ & $115.4 / 6.72$ and 6.94 & $\mathrm{C}_{5}-\mathrm{H}_{5}$ in guaiacyl units $(\mathbf{G})$ \\
\hline $\mathrm{G}_{6}$ & $119.5 / 6.77$ & $\mathrm{C}_{6}-\mathrm{H}_{6}$ in guaiacyl units $(\mathbf{G})$ \\
\hline $\mathrm{J}_{\beta}$ & $126.7 / 6.77$ & $\begin{array}{l}\mathrm{C}_{\beta}-\mathrm{H}_{\beta} \text { in cinnamyl aldehyde end-groups } \\
\text { (J) }\end{array}$ \\
\hline $\mathrm{I}_{\beta}$ & $129.0 / 6.23$ & $\mathrm{C}_{\beta}-\mathrm{H}_{\beta}$ in cinnamyl alcohol end-groups (I) \\
\hline $\mathrm{I}_{\alpha}$ & $129.0 / 6.45$ & $\mathrm{C}_{\alpha}-\mathrm{H}_{\alpha}$ in cinnamyl alcohol end-groups (I) \\
\hline $\mathrm{J}_{\alpha}$ & $153.8 / 7.63$ & $\begin{array}{l}\mathrm{C}_{\alpha}-\mathrm{H}_{\alpha} \text { in cinnamyl aldehyde end-groups } \\
\text { (J) }\end{array}$ \\
\hline
\end{tabular}

lations for $\mathrm{C}_{2}-\mathrm{H}_{2}\left(\delta_{\mathrm{C}} / \delta_{\mathrm{H}} 111.6 / 6.99 \mathrm{ppm}\right), \mathrm{C}_{5}-\mathrm{H}_{5}\left(\delta_{\mathrm{C}} / \delta_{\mathrm{H}} 115.4 / 6.72\right.$ and 6.94) and $\mathrm{C}_{6}-\mathrm{H}_{6}\left(\delta_{\mathrm{C}} / \delta_{\mathrm{H}} 119.5 / 6.77 \mathrm{ppm}\right)$. The double $\mathrm{C}_{5}-\mathrm{H}_{5}$ signal revealed some heterogeneity among the $\mathrm{G}$ units especially affecting the $\mathrm{C}_{5}-\mathrm{H}_{5}$ correlation, probably because it is due to different substituents at $C_{4}$ (e.g. phenolic or etherified in different substructures). Signals corresponding to $\mathrm{C}_{2,6}-\mathrm{H}_{2,6}$ correlations in $\mathrm{C}_{\alpha}$-oxidized S-lignin units $\left(\mathbf{S}^{\prime}\right)$ were observed at $\delta_{\mathrm{C}} / \delta_{\mathrm{H}} 106.8 / 7.32$ and 107.0/7.19. Signals of H-lignin units were not detected in the HSQC spectrum, in agreement with the low proportions of $\mathrm{H}$ units (ca. 1\%) observed by Py-GC/MS. The NMR estimation of the S/G ratio of paulownia MWL is included in Table 2, and accounts for 0.66 , in agreement with the results obtained upon Py-GC/MS. Other signals in this HSQC region of the spectrum are from cinnamyl alcohol end-groups (I), with their $\mathrm{C}_{\alpha}-\mathrm{H}_{\alpha}$ and $\mathrm{C}_{\beta}-\mathrm{H}_{\beta}$ correlations observed at $\delta_{\mathrm{C}} / \delta_{\mathrm{H}} 129.0 / 6.23$ and $129.0 / 6.45 \mathrm{ppm}$, respectively; and cinnamaldehyde end-groups (J), with the $\mathrm{C}_{\alpha}-\mathrm{H}_{\alpha}$ and $\mathrm{C}_{\beta}-\mathrm{H}_{\beta}$ correlations observed at $\delta_{\mathrm{C}} / \delta_{\mathrm{H}} 153.8 / 7.63$ and $126.7 / 6.77 \mathrm{ppm}$, respectively. The total relative content of the cinnamaldehyde endgroups was estimated by comparison of the intensities of the $\mathrm{C}_{\beta}-\mathrm{H}_{\beta}$ correlations in cinnamyl alcohols (I) and aldehydes (J). The aromatic cross-signals of the cinnamyl alcohol end-groups overlapped with the same signals in lignin S and G units. However, this was not the case for some of the cinnamaldehyde aromatic crosssignals revealing the presence of (i) sinapaldehyde end-groups $\left(\mathbf{J}_{(\mathrm{S})}\right)$, characterized by an unique $\mathrm{C}_{2,6}-\mathrm{H}_{2,6}$ correlation signal at $\delta_{\mathrm{C}} / \delta_{\mathrm{H}} 106.8 / 7.06 \mathrm{ppm}$, and (ii) coniferaldehyde end-groups $\left(\mathbf{J}_{(\mathrm{G})}\right)$, characterized by $\mathrm{C}_{2}-\mathrm{H}_{2}$ and $\mathrm{C}_{6}-\mathrm{H}_{6}$ correlation signals at around $\delta_{\mathrm{C}} / \delta_{\mathrm{H}} 111 / 7.4$ and $123 . / 7.2 \mathrm{ppm}$, respectively.

\section{Table 3}

Structural characteristics (percentage of lignin side-chains forming different inter-unit linkages A-F and cinnamyl end-groups I, J, referred to as the total side-chains; $\mathrm{H}, \mathrm{G}$ and $\mathrm{S}$ contents, $\mathrm{S} / \mathrm{G}$ ratio, phenolic content, as \% of $\mathrm{H}+\mathrm{G}+\mathrm{S}$ after MWL acetylation, and phenolic-to-aliphatic hydroxyl ratio) from integration of ${ }^{13} \mathrm{C}-{ }^{1} \mathrm{H}$ correlation signals in the HSQC spectrum of MWL from Paulownia fortunei wood.

\begin{tabular}{lc}
\hline Linkage relative abundance (\% side-chains involved) & \\
$\beta-O-4^{\prime}$ structures (A) & 62 \\
Resinols (B) & 12 \\
Phenylcoumarans (C) & 11 \\
Spirodienones (D) & 3 \\
$\beta-1^{\prime}$ structures (E) & 1 \\
Dibenzodioxocins (F) & 2 \\
Cinnamyl alcohol end-groups (I) & 4 \\
Cinnamyl aldehyde end-groups (J) & 5 \\
Percentage of lignin units & \\
H (\%) & 0 \\
G (\%) & 60 \\
S (\%) & 40 \\
S/G ratio & 0.66 \\
Phenolic content (\%) & 16 \\
Phenolic/aliphatic hydroxyls ratio & 0.14 \\
\hline
\end{tabular}

The relative abundances of the main inter-unit linkages (referred to as the total side-chains) present in the paulownia MWL, as well as the relative abundance of the $H, G$ and $S$ units and the molar S/G ratio, calculated from the HSQC spectrum, are shown in Table 3. In addition, the phenolic content and the phenolic-toaliphatic hydroxyl ratio were estimated from the HSQC after MWL acetylation, and are also included in the table. The main substructure present in paulownia MWL was the $\beta-0-4^{\prime}$ aryl ether ones (A), that accounts for $62 \%$ of all side-chains, followed by the $\beta$ $\beta^{\prime}$ resinol substructures (B) that involved $12 \%$ of all side-chains and the $\beta-5^{\prime}$ phenylcoumaran structures $(\mathbf{C})$ with $11 \%$. The rest of substructures, such as spirodienones $(\mathbf{D}), \beta-1^{\prime}$ structures $(\mathbf{E})$, dibenzodioxocins (F), and cinnamyl end-groups ( $\mathbf{I}$ and $\mathbf{J})$ were present in lower proportions. Comparing to other hardwoods commonly used for papermaking, such as eucalypt wood (Rencoret et al., 2008), the lignin from paulownia presents a lower proportion of $\beta-0-4^{\prime}$ ether linkages, and a higher proportion of carbon-carbon linked (condensed) structures (such as $\beta-\beta^{\prime}, \beta-5^{\prime}, 5-5^{\prime}$ and $\beta-1^{\prime}$ ) and a lower S/G ratio. Since the $\beta-0-4^{\prime}$ ether linkages are cleaved to a high extent during alkaline cooking, while condensed linkages resist alkaline cooking conditions (Gierer, 1985; Gierer and Norén, 1980; Ibarra et al., 2007a), the relatively high content of condensed structures in the lignin from paulownia wood will make this wood more resistant to alkaline delignification.

\section{Conclusions}

The MWL isolated from $P$. fortunei has been characterized by Py-GC/MS and 2D-NMR techniques. A predominance of guaiacyl (G) over syringyl (S) lignin moieties was found in this wood lignin, with a H:G:S molar composition of 1:59:40. The main inter-unit linkages present in paulownia MWL were the $\beta-0-4^{\prime}$ ether bonds (62\% of all side-chains) followed by $\beta-\beta^{\prime}$ resinol-type (12\%) and $\beta$ $5^{\prime}$ phenylcoumaran substructures (11\%), and with lower amounts of $\beta-1^{\prime}$, spirodienone and 5-5' dibenzodioxocin substructures. The high lignin content (ca. 23\% Klason lignin) together with the high amounts of G-lignin units (S/G ratio of 0.66) and condensed structures would contribute to the lower reactivity of paulownia lignin during pulping.

\section{Acknowledgements}

This study has been funded by the Spanish project AGL200501748 and the BIORENEW EU-Project (NMP2-CT-2006-026456) 
Prof. Manuel J. Díaz (University of Huelva, Spain) is acknowledged for providing the sample of paulownia. J.R. thanks the CSIC for an I3P fellowship and G.M. thanks the Spanish MEC for a FPI fellowship.

\section{References}

Ämmälahti, E., Brunow, G., Bardet, M., Robert, D., Kilpeläinen, I., 1998. Identification of side-chain structures in a poplar lignin using three-dimensional HMQCHOHAHA NMR spectroscopy. J. Agric. Food Chem. 46, 5113-5117.

Balakshin, M.Y., Capanema, E.A., Chen, C.-L., Gracz, H.S., 2003. Elucidation of the structures of residual and dissolved pine kraft lignins using an HMOC NMR technique. J. Agric. Food Chem. 51, 6116-6127.

Balakshin, M.Y., Capanema, E.A., Goldfarb, B., Frampton, J., Kadla, J.F., 2005. NMR studies on Fraser fir Abies fraseri (Pursh) Poir lignins. Holzforschung 59, 488-496.

Bergmann, B.A., 1998. Propagation method influences first year field survival and growth of Paulownia. New Forests 16, 251-264.

Björkman, A., 1956. Studies on finely divided wood. Part I. Extraction of lignin with neutral solvents. Sven. Papperstidn. 13, 477-485.

Capanema, E.A., Balakshin, M.Y., Chen, C.-L., Gratzl, J.S., Gracz, H., 2001. Structura analysis of residual and technical lignins by ${ }^{1} \mathrm{H}-{ }^{13} \mathrm{C}$ correlation 2D NMRspectroscopy. Holzforschung 55, 302-308.

Capanema, E.A., Balakshin, M.Y., Kadla, J.F., 2004. A comprehensive approach for quantitative lignin characterization by NMR spectroscopy. J. Agric. Food Chem. $52,1850-1860$

Capanema, E.A., Balakshin, M.Y., Kadla, J.F., 2005. Quantitative characterization of a hardwood milled wood lignin by nuclear magnetic resonance spectroscopy. J. Agric. Food Chem. 53, 9639-9649.

Caparrós, S., Ariza, J., Garrote, G., López, F., Díaz, M.J., 2007. Optimization of Paulownia fortunei L. autohydrolysis-organosolv pulping as a source of xylooligomers and cellulose pulp. Ind. Eng. Chem. Res. 46, 623-631.

Caparrós, S., Díaz, M.J., Ariza, J., López, F., Jiménez, L., 2008. New perspectives for Paulownia fortunei $\mathrm{L}$. valorisation of the autohydrolysis and pulping processes. Bioresour. Technol. 99, 741-749.

Chang, H.M., Sarkanen, K.V., 1973. Species variation in lignin. Effect of species on the rate of kraft delignification. Tappi 56, 132-134.

del Río, J.C., Gutiérrez, A., Hernando, M., Landín, P., Romero, J., Martínez, A.T., 2005. Determining the influence of eucalypt lignin composition in paper pulp yield using Py-GC/MS. J. Anal. Appl. Pyrol. 74, 110-115.

del Río, J.C., Rencoret, J., Marques, G., Gutiérrez, A., Ibarra, D., Santos, J.I., JiménezBarbero, J., Zhang, L., Martínez, A.T., 2008. Highly acylated (acetylated and/or p-coumaroylated) native lignins from diverse herbaceous plants. J. Agric. Food Chem. 56, 9525-9534.

Ede, F.J., Auger, M., Green, T.G.A., 1997. Optimizing root cutting success in Paulowni spp. J. Hortic. Sci. 72, 179-185.

Faix, O., Meier, D., Fortmann, I., 1990. Thermal degradation products of wood. A collection of electron-impact (EI) mass spectra of monomeric lignin derived products. Holz Roh-Werkstoff 48, 351-354.

Gierer, J., 1985. Chemistry of delignification. Part I: General concept and reactions during pulping. Wood Sci. Technol. 19, 289-312.

Gierer, J., Norén, I., 1980. On the course of delignification during Kraft pulping. Holz forschung 34, 197-200.

Gonçalves, V.M.F., Evtuguin, D.V., Domingues, M.R.M., 2008. Structural charac terization of the acetylated heteroxylan from the natural hybrid Paulownia elongata/Paulownia fortunei. Carbohydr. Res. 343, 256-266.

González-Vila, F.J., Almendros, G., del Río, J.C., Martín, F., Gutiérrez, A., Romero, J. 1999. Ease of delignification assessment of different Eucalyptus wood species by pyrolysis (TMAH)-GC/MS and CP/MAS ${ }^{13}$ C-NMR spectrometry. J. Anal. Appl. Pyrol. 49, 295-305.

Heikkinen, S., Toikka, M.M., Karhunen, P.T., Kilpeläinen, I., 2003. A. Quantitative 2D $\mathrm{HSOC}$ (Q-HSOC) via suppression of J-dependence of polarization transfer in NMR spectroscopy: application to wood lignin. J. Am. Chem. Soc. 125, 4362-4367.

Holtman, K.H., Chang, H.M., Jameel, H., Kadla, J.F., 2006. Quantitative ${ }^{13}$ C NMR characterization of milled wood lignins isolated by different milling techniques. J. Wood Chem. Technol. 26, 21-34.

Ibarra, D., Chávez, M.I., Rencoret, J., del Río, J.C., Gutiérrez, A., Romero, J., Camarero S., Martinez, M.J., Jiménez-Barbero, J., Martínez, A.T., 2007a. Lignin modification during Eucalyptus globulus kraft pulping followed by totally chlorine free bleaching: a two-dimensional nuclear magnetic resonance, Fourier transform infrared, and pyrolysis-gas chromatography/mass spectrometry study. J. Agric. Food Chem. 55, 3477-3499.
Ibarra, D., Chávez, M.I., Rencoret, J., del Río, J.C., Gutiérrez, A., Romero, J., Camarero, S. Martínez, M.J., Jimenez-Barbero, J., Martínez, A.T., 2007b. Structural modification of eucalypt pulp lignin in a totally chlorine free bleaching sequence including a laccase-mediator stage. Holzforschung 61, 634-646.

Jiménez, L., Rodriguez, A., Ferrer, J.L., Pérez, A., Angulo, V., 2005. Paulownia, a fastgrowing plant, as a raw material for paper manufacturing. Afinidad 62, 100-105

Karhunen, P., Rummakko, P., Sipilä, J., Brunow, G., Kilpeläinen, I., 1995. Dibenzodioxocins-a novel type of linkage in softwood lignins. Tetrahedron Lett. $36,169-170$.

Kukkola, E., Koutaniemi, S., Pöllänen, E., Gustafsson, M., Karhunen, P., Lundell, T.K. Saranpää, P., Kilpeläinen, I., Teeri, T.H., Fagerstedt, K.V., 2004. The dibenzodioxocin lignin substructure is abundant in the inner part of the secondary wall in Norway spruce and silver birch xylem. Planta 218, 497-500.

Liitiä, T.M., Maunu, S.L., Hortling, B., Toikka, M., Kilpeläinen, I., 2003. Analysis of technical lignins by two- and three-dimensional NMR spectroscopy. J. Agric. Food Chem. 51, 2136-2143.

Lundquist, K., 1987. On the occurrence of $\beta-1$ structures in lignin. J. Wood Chem. Technol. 7, 179-185.

Marques, G., Gutiérrez, A., del Río, J.C., 2008. Chemical composition of lignin and lipids from tagasaste (Chamaecytisus proliferus spp. palmensis). Ind. Crops Prod. $28,29-36$.

Martínez, A.T., Rencoret, J., Marques, G., Gutiérrez, A., Ibarra, D., Jiménez-Barbero, J., del Río, J.C., 2008. Monolignol acylation and lignin structure in some nonwoody plants: a 2D NMR study. Phytochemistry 69, 2831-2843.

Olson, J.R., Carpenter, S.B., 1985. Specific gravity, fiber length, and extractive content of young paulownia. Wood Fiber Sci. 17, 428-433.

Rai, A.K., Singh, S.P., Luxmi, C., Savita, G., 2000. Paulownia fortunei-a new fiber source for pulp and paper. Indian Pulp Pap. Tech. Assoc. 12, 51-56.

Ralph, J., Hatfield, R.D., 1991. Pyrolysis-GC-MS characterization of forage materials. J. Agric. Food Chem. 39, 1426-1437.

Ralph, J., Lundquist, K., Brunow, G., Lu, F., Kim, H., Schatz, P.F., Marita, J.M., Hatfield R.D., Ralph, S.A., Christensen, J.H., Boerjan, W., 2004a. Lignins: natural polymers from oxidative coupling of 4-hydroxyphenylpropanoids. Phytochem. Rev. 3, 29-60.

Ralph, J., Marita, J.M., Ralph, S.A., Hatfield, R.D., Lu, F., Ede, R.M., Peng, J., Quideau, S., Helm, R.F., Grabber, J.H., Kim, H., Jimenez-Monteon, G., Zhang, Y., Jung, H.J.G., Landucci, L.L., MacKay, J.J., Sederoff, R.R., Chapple, C., Boudet, A.M., 1999. Solution-state NMR of lignin. In: Argyropoulos, D.S. (Ed.), Advances in Lignocellulosics Characterization. Tappi Press, Atlanta, USA, pp. 55-108.

Ralph, S.A., Ralph, J., Landucci, L., 2004b. NMR Database of Lignin and Cell Wall Model Compounds. US Forest Prod. Lab., Madison, WI (http://ars.usda.gov/ Services/docs.htm?docid=10491) (accessed: July 2006).

Rencoret, J., Gutiérrez, A., del Río, J.C., 2007. Lipid and lignin composition of woods from different eucalypt species. Holzforschung 61, 165-174.

Rencoret, J., Marques, G., Gutiérrez, A., Ibarra, D., Li, J., Gellerstedt, G., Santos, J.I. Jiménez-Barbero, J., Martínez, A.T. del Río, J.C., 2008. Structural characterization of milled wood lignin from different eucalypt species. Holzforschung 62 , 514-526.

Rodrigues, J., Meier, D., Faix, O., Pereira, H., 1999. Determination of tree to tree variation in syringyl/guaiacyl ratio of Eucalyptus globulus wood lignin by analytical pyrolysis. J. Anal. Appl. Pyrol. 48, 121-128.

Silvestre, A.J.D., Evtuguin, D.V., Sousa, A.P.M., Silva, A.M.S., 2005. Lignans from a hybrid Paulownia wood. Biochem. Syst. Ecol. 33, 1298-1302.

Tappi 2004-2005, 2004. TAPPI Test Methods. TAPPI Press, Norcoss, GA, USA

Tsutsumi, Y., Kondo, R., Sakai, K., Imamura, H., 1995. The difference of reactivity between syringyl lignin and guaiacyl lignin in alkaline systems. Holzforschung 49, 423-428.

Yokoi, H., Ishida, Y., Ohtani, H., Tsuge, S., Sonoda, T., Ona, T., 1999. Characterization of within-tree variation of lignin components in Eucalyptus camaldulensis by pyrolysis-gas chromatography. Analyst 124, 669-674.

Yokoi, H., Nakase, T., Ishida, Y., Ohtani, H., Tsuge, S., Sonoda, T., Ona, T., 2001. Discriminative analysis of Eucalyptus camaldulensis grown from seeds of various origins based on lignin components measured by pyrolysis-gas chromatography. J. Anal. Appl. Pyrol. 57, 145-152.

Zhang, L., Gellerstedt, G., 2001. NMR observation of a new lignin structure, a spirodienone. Chem. Commun., 2744-2745.

Zhang, L.M., Gellerstedt, G., Ralph, J., Lu, F.C., 2006. NMR studies on the occurrence of spirodienone structures in lignins. J. Wood Chem. Technol. 26, 65-79.

Zhang, L., Gellerstedt, G., 2007. Quantitative 2D HSQC NMR determination of polymer structures by selecting the suitable internal standard references. Magn. Reson. Chem. 45, 37-45. 